\title{
Video Use in Reflective Practice: Experience from Educating Speech and Language Therapists
}

Jane Stokes, School of Health and Social Care, University of Greenwich and Keena Cummins, independent speech and language therapist and visiting tutor, City University, London and University of Greenwich

\begin{abstract}
This case study shares the experiences of speech and language therapy lecturers in higher education using video with students and practitioners to support reflective practice. The authors believe that video forms a fundamental role in developing the core skills of health, social and education professionals. Frequently teachers in higher education and students alike present with a reluctance to engage with the use of video. Possible reasons for this are discussed. The importance of careful preparatory and debriefing sessions is emphasized, as is the need for an observation schedule. The key ingredients to ensuring that video is effective as a learning tool as well as the challenges are examined. The experience may well have resonance with others in higher education involved in the development of critical reflection associated with students' communication and interaction.
\end{abstract}

\section{Context}

Within speech and language therapy clinical practice, the use of video recording is accepted as a part of the therapist's range of resources. It is regularly used to document communication difficulties during therapy sessions, as an adjunct to therapy with families, and as a teaching tool. It is increasingly being used as a tool for supporting parents in selfreflection and in some departments is used in staff continuing professional development, peer supervision and service development. Students studying to be speech and language therapists in the UK are regularly expected to make video recordings of their practice sessions (always with specific written consent from the clients) in order to reflect on their evolving interaction and therapeutic skills. Students report that by looking back at the video they can see far more of their nonverbal as well as verbal communication and are able to see the developments both in their clients and themselves week on week.

However, in our many years of clinical practice in managing and training speech and language therapists and education and health care professionals we have frequently been confronted by what initially appears to be a 'deep reluctance' amongst clinical tutors, practitioners and their managers/teachers to use video for self- reflection. This is in stark contrast to the widely espoused view that health and social care practitioners are expected to engage in regular reflective practice. Much has been written about the importance of reflective practice e.g. reflective logs in educating health and social care professionals (Jasper 2003; Oelofsen 2012) with little written about the benefits of video. This is changing. The recent publication by Kennedy et al (2011) shows the very diverse fields within social services and health in which video is now being used. We describe below a project for integrating video self-reflection into a pre-registration programme for speech and language therapists. This project aimed to tackle placement educators' often expressed reluctance to 
the use of video and to ensure that students gain the most benefit from the use of video in reflective practice.

\section{Project}

In setting up a new postgraduate diploma programme for speech and language therapists in 2006, a collaborative venture between University of Greenwich and Canterbury Christ Church University, we prioritised facilities for supporting student self-reflection. A case was made for every student on the programme to have access to both video and audio recording devices for use both during campus based activities and on placement. A computing lab was set up to support students with access to a range of both commercially produced and custom-made video clips to aid their learning. In order to investigate optimum use of these facilities across courses we enquired into the use of video in nursing, midwifery, social work and occupational therapy programmes at the University and were surprised to learn that generally these other programmes did not include the use of self-video playback although they did use commercially and self-developed video clips to support lectures and to create self-directed learning.

Having developed an Early Years speech and language therapy service for parents, practitioners and therapists with video at its centre, we have extensive experience of the additional depth that self-analysis using video can provide. Speech and language therapy student practitioners are encouraged, while on placement, to make videos of themselves working with clients. Students are introduced to this process carefully through campus-based preparatory sessions. From our experience in facilitating video reflection with speech and language therapy students, clinicians and education practitioners, the process of video reflection needs to be established within a course of a minimum of four weeks.

Prior to the actual making of the video, sessions are provided to support individuals in redefining what we mean by video and ensuring that there is a process over time in which they are supported through risk, challenge and change. It is important to specify and agree who the video can be seen by (either just the placement educator and the student or the student and a small group), what it is going to be used for and whether and where it is going to be kept (deleted on completion of a course if requested). The students need to be introduced to the theory and evidence around practitioner management of their interaction/attunement techniques (Kennedy et al 2011) and the value of watching themselves on video in relation to the second by second analysis of the body language between therapist and the client - the impact of the therapist's behaviours on another. Without the video it is impossible to reflect on these behaviours. In these sessions we establish how much control the student has and emphasise that the use of video actually empowers the student. The student can use the video to choose certain elements to show their placement educator and watch each moment with them. This replaces the traditional model on placement of being observed and then reflecting - in which the two individuals remember very different things and are unable to analyse them at a micro-level. We have found that the model of video works optimally when the student is able to return to the same scenario/client over a period of a minimum of four weeks. This allows the student to analyse their skills, experiment with the strategies that they have become mindful of, strip down their communication skills and gradually build them up in relation to client response. 
The student needs to be made familiar with the process of 'videoing'. This is increasingly easy with cameras which can be balanced at the edge of a room, do not require a camera person, and can be switched on at any time almost as a 'fly on the wall'. The student is also told what to film; 3-5 minutes of an interaction with a client (e.g. a play session with a child, or an interview with a parent).

When the video has been completed it is brought back to the placement educator and the student takes on the responsibility of 'showing' the video. In this situation they are given control. They are provided with an evaluation form with interaction techniques specified and then watch the video which is played for approximately three minutes. The student is then invited to comment on what they notice about their skills using the categories listed on the evaluation sheet. It is likely that they will firstly verbalise the 'surface details' referred to earlier. This is a necessary part of the reflection and helps the student to de-sensitise 'themselves' and they will then start to comment on their behaviours. The educator is then able to highlight each individual strength and the immediate impact it had on the client, specifying the research that supports the strategy. Seeing oneself perform successfully provides the ultimate in role models (Bellini \& Akullian 2007) The student is then able to pick a particular strategy within their repertoire to utilise even more and then return to the client and experiment with the strategy looking at its impact. They return with a new video, reanalyse it, scaffold on another strategy and then work with the client again - reviewing their impact and the change in the client. The student and placement educator watch the process of change over time so that the video becomes a record of the student's evolving skills and the client's development. The student is involved in evaluation of their skills throughout, sees their emerging skills and can debate and discuss the expectations of the educator. The 'material' can be added to at regular intervals and the individual can witness their progress over weeks, months or even years. These videos complement the educator's perspective of the student's development. The videos can also be held by an individual and taken with them (with consent from both people involved) to show new supervisors the change in the student or indeed the client can hold the video to show their own progression.

\section{Discussion}

The opportunity to reflect on one's own communication and interaction styles is fundamental to the development of the competency of any health and social care professional. Emerging research would suggest that it is the interaction and attunement of the practitioner with the client that most influences the outcome of intervention and that the singular most successful way of developing interaction and communication skills is through video (Kennedy et al 2011). The use of an observation schedule is vital; Fukkink et al (2011, p. 57) support our belief that detailed analysis of an individual's communication using video together with observation schedules is 'more effective than other instructional components, such as explaining, modeling, and practicing the target skills'

and that it is 'feedback that is probably the most crucial dimension in terms of changing the trainee's behavior'.

The 'deep reluctance' first perceived on meeting those unfamiliar with the benefits of video we believe to be related to anxiety and possible 'aversion' based on past personal experience of video. Issues of assessment and surveillance get confused with the use of 
video as a self-reflective tool. The ubiquitous nature of mobile technology, reality TV and Youtube mean that there is potential for video to be used in a critical or undermining way. People are therefore reluctant to expose themselves for fear of being demeaned or denigrated. They are rightly fearful of how the video is going to be used, who it is going to be shown to and how it is going to be analysed and judged. They may well feel a lack of control. They are frequently unhappy with their physical appearance and are anxious at being confronted by an image of themselves in action (something we rarely see). Video and seeing oneself in action can present as overwhelming. A very common response when watching oneself on video are comments such as 'I hate seeing myself back... My voice sounds strange... I never realised I did that with my face when I talk'. The individual can become 'mired in surface details such as their personal appearance or how they sound, without reaching deeper levels of analysis and understanding' (Pailliotet, 1995,p138). 'When viewing a video of yourself, unsupported it is very easy to get stuck in a negative cycle. The fear of humiliation from seeing how bad you are/look/sound is very real... it is easy to get stuck in a negative cycle... which can prevent most exploratory learning... All this can be ameliorated by a skilled guider-facilitator' (Cave et al 2011 p186).

In introducing video reflection in a speech and language therapy service (Cummins \& Hulme 1997; Cummins, Pullen \& Hulme 2012,) we have found that the initial reluctance can be tackled by a philosophy of supported, systematic, stepped supervision, which is ongoing over time. In using video reflection in student education we have endeavoured to replicate this through the use of campus-based preparatory and debriefing sessions which create a framework to build on strengths as a 'dialogue mediated by video' (Cave et al 2011 p181). The video provides a fulcrum for hypothesising about interaction, implementing and evaluating change over time. McCluskey (2005) suggests that people become defensive in their communication when they are anxious, under stress or frightened and that the individual needs 'a response which puts them in touch with their competence to act: a response that reactivates their emotional, physical, intellectual capacity: a response which allows them to make use of the resources available to them' (McCluskey 2005 p X1X) The video provides them with time to reflect, concrete skills to observe and clear examples of their own competencies on which to build.

Being specific about what is required on video, how long for and what is being observed supports the student in knowing exactly what is expected of them and supports them in feeling in control of their observations and feedback. There is 'increased motivation to learn from building on strengths' (Brown \& Rutter 2006). As the educator and students observe together, so they are able to clarify shared meanings and vocabulary based on the behaviour of the student and the impact on the client. Moment by moment impact can be identified through freeze frame. The video keeps them focused in the 'here and now'. By engaging in dialogue, 'grounding' (Brennan et al 2010) occurs. In looking at the image on the screen the educator and student are supported in the convergence and synchronisation of thought between them resulting in joint learning and extension of mutual ideas.

Throughout the course of the videoed sessions the student has access to experiential learning, provides evidence for their own hunches and opportunities to explore skills and competencies using the eyes of an observer rather than a performer. 


\section{Evaluation}

The evaluation of this project is at an early stage but to date we have had some very positive feedback from students. They report:

Being able to watch yourself helps better planning of your next session... l'd happily watch back a video of my session, "forcing" myself to reflect more than I would without a video.

I plan on keeping some of my videos to look back on them... It seems that it would be a lot easier, more enjoyable and objective to look back at a video than to read an old reflection

but

I wouldn't want to use it to the exclusion of more traditional means of reflection. The benefits are that you can see what did not go well but also things that you actually did better than you thought.

Being able to revisit an experience through watching a video... gave me the opportunity to notice things that otherwise I would not have been aware of.

Students also commented that in a supportive setting, it was very useful to look at the videos in pairs or groups:

Others can help you change your mindset, and point out if you are being unjustifiably hard on yourself.

It helped me see that sometimes what happens on the inside is not what transpires on the outside and that my performance was not as bad as it felt when I was immersed in it.

Through this project we have developed an understanding of the key ingredients to making video self-reflection effective as a learning tool. We have learned that it is essential to have preparatory sessions, conducted by experienced practitioners, sensitising the students to the process and function of using video. It is important to have evaluation forms to structure the reflection. It is also important to encourage a non-judgmental approach. We plan to continue evaluating this approach and feel that it has application across a wide range of education programmes for health, social care and education students. Additionally, programmes that prepare students for the world of commerce, and public relations may well benefit from adopting the principles and processes outlined.

\section{Limitations}

There are undoubtedly challenges to embedding this approach into student education. Consent can be difficult to obtain, with the definition of informed consent particularly problematic in relation to people with communication difficulties. Clear data protection protocols are essential to support the obtaining of consent by the students on practice. It can also be difficult to facilitate continuity of contact over time, with the opportunity for the 
student to see the same client in order to develop skills. It is important that these issues are thought through in advance and that the placement educators are aware of the importance of overcoming these barriers in the interest of the student.

\section{Concluding remarks}

It is our view that true reflective practice is incomplete without the regular use of video. If a person uses only writing to reflect on their communication, this usually only includes their perception and memory of how they saw things, not their impact moment by moment and the effect on the partner in the communication dyad. From the experience of this project, we believe that students preparing to work in any profession that values the importance of communication and interaction skills should be introduced to video from the outset. The use of video itself, however, needs to be used as part of a reflective practice approach, managed by skilled facilitators who are themselves confident in the use of video, familiar with interaction/attunement theory and mindful of the 'challenge of work cultures and the preconceived ideas which are embedded in practice'(Fook \& Askeland 2007 p 522). It is our experience that allowing students access to this powerful and proven tool for reflective practice greatly enhances their ability to develop their communication and interaction.

\section{References}

Bellini, X. and Akullian, Y. (2007) 'A meta-analysis of video modeling and video selfmodeling interventions for children and adolescents with autism spectrum disorders.' Exceptional Children 73(3), 264-287.

Brennan, S. Galati, A. and Kuhlen, A. (2010) 'Two Minds, One Dialog: Coordinating speaking and understanding in the psychology of learning and motivation'. In Ross, B.H. (ed) The Psychology of Learning and Motivation: Advances in Research and Theory, Vol. 53, Burlington: Academic Press, 301-344.

Brown, K. and Rutter, L. (2006) Critical Thinking: A Guide in Enhancing, Learning and Writing for Post Qualifying Social Work Programmes. Exeter: Learning Matters Limited.

Cave, R. Roger, A. and Young, R. (2011) 'Enhancing Teacher and Student interactions in Higher Education through Video Enhanced Reflective Practice' in Kennedy, H.; Landor, M. and Todd, L. (eds) Video Interaction Guidance: A relationship-based intervention to promote attunement, empathy and wellbeing London: Jessica Kingsley, chapter 11 pp181-197.

Landor, M. and Todd, L. (2011) Video Interaction Guidance: A relationship-based intervention to promote attunement, empathy and wellbeing. London: Jessica Kingsley.

Cummins, K. and Hulme, S. (1997) 'Video: a reflective tool.' Speech and language therapy in practice, Autumn, 4-7

Cummins, K. Pullen, K. and Hulme, S. (2012) 'Managing pre-school children in community settings' in Kersner, M. and Wright, J. (eds). Speech and language therapy the decision making process when working with children. London: Routledge chapter 4 pp 39-46.

Fook, J. and Askeland, G. (2007) 'Challenges of Critical Reflection: "Nothing Ventured, Nothing Gained."'Social Work Education, 25(6), 520-533. 
Fukkink, R. Trienekens, N. and Kramer, L. (2011) 'Video feedback in Education and Training: Putting Learning in the Picture'. Education Psychology Review, 23(1) 45-63.

Jasper, M. (2003) Beginning Reflective Practice: foundations in nursing and healthcare. Cheltenham: Nelson Thornes.

Kennedy, H. Landor, M. and Todd, L. (2011) Video Interaction Guidance: A relationshipbased intervention to promote attunement, empathy and wellbeing. London:Jessica Kingsley.

McCluskey, U. (2005) To be met as a person - the dynamics of attachment in professional encounters. London: Karnac books.

Oelofsen, N. (2012) Developing reflective practice: a guide for students and practitioners of health and social care. Banbury: Lantern.

Pailliotet, A. (1995) 'I never saw that before: a deeper view of video analysis in teacher education'. Teacher Educator, 31(2), 138-156.

\section{Author Biographies}

Jane Stokes worked in the NHS as a speech and language therapist with children and families for over 25 years before taking up the post of senior lecturer with responsibility for establishing the PGDip in Speech and Language therapy run collaboratively by University of Greenwich and Canterbury Christ Church.

Keena Cummins is a speech and language therapist who has worked in both the NHS and in the private and voluntary sector and has specialised for the last twenty years in the use of video to support parents, therapists, students and professionals in reflecting on their skills. 